\title{
Comment of the Editor: C2-C1 transarticular fixation
}

\author{
Max Aebi
}

Received: 7 June 2014/Revised: 7 June 2014/Accepted: 7 June 2014/Published online: 2 July 2014

(C) Springer-Verlag Berlin Heidelberg 2014

The Letter to the Editor of R.E.E. Omaña et al. concerning "Anterior Pedicle Screw Fixation of C2: An Anatomic Analysis of Axis Morphology and Simulated Surgical Fixation" and the response on it by Zeng-Hui Wu et al. is a valuable contribution to optimize anterior pedicle screw fixation of $\mathrm{C} 2$ in the stabilization of $\mathrm{C} 1 / \mathrm{C} 2$ dislocation.

However, I wonder why these authors are so much "fixed" on an anterior screw placement as an adjunct to stabilize the segment C1/C2 from the front.

This is indeed not a simple technique and induces all the difficulties and risks of a transoral surgery. There is a wellestablished alternative, which can be achieved through a "classical" anterolateral cervical approach at the level of C5, exactly like the approach for an anterior odontoid screw fixation. With the proper retractor systems, this approach can even be performed as a minimally invasive procedure. The specific anatomic structure of the massa lateralis of $\mathrm{C} 2$ with the superior part of it overlapping anteriorly like a terrace the anterior transarticular $\mathrm{C} 2-\mathrm{C} 1$ screw fixation is relatively easy to be performed. The reduced joint $\mathrm{C} 1 / \mathrm{C} 2$ can be held with a $\mathrm{K}$-wire, which acts additionally as a guide wire for the self-cutting cannulated screws.

This technique is extensively described in the AOManual for Spine Surgery as well as in the original literature [1-3]. It is a pity that the authors do not cite this elegant technique as an alternative to a somewhat cumbersome technique.

Furthermore, it may not be of relevance that we have to extend the anatomical studies to other races and gender dependent, since every surgeon, who decides to use this rare technique should anyway evaluate the anatomical landmarks of the specific patient to be treated in order to plan the surgery as safely as possible.

Conflict of interest None.

\section{References}

1. Aebi M (2010) Surgical treatment of upper, middle and lower cervical injuries and non-unions by anterior procedures. Eur Spine J 19(Suppl 1):S33-S39

2. Sen MK, Steffen T, Beckman L, Tsantrizos A, Reindl R, Aebi M (2005) Atlantoaxial fusion using anterior transarticular screw fixation of C1-C2: technical innovation and biomechanical study. Eur Spine J 14(5):512-518

3. Reindl R, Sen M, Aebi M (2003) Anterior instrumentation for traumatic C1-C2 instability. Spine (Phila Pa 1976) 28(17):E329E333
M. Aebi $(\bowtie)$

Orthopaedic Department, Hislanden Salem Hospital,

3000 Bern 25, Switzerland

e-mail: max.aebi@MEMcenter.unibe.ch 